\title{
ORIGINAL ARTICLE Histopathology and cholinergic assessment of Pterocarya fraxinifolia on chicken embryo
}

\author{
Parisa SADIGHARA 1, Javad ASHRAFIHELAN 2 , Abbas BARIN ${ }^{3}$, Tahreh ALI ESFAHANI 1 \\ 1 Department of toxicology, Faculty of veterinary, Tehran University, Tehran, Iran \\ 2 Department of pathobiology, Faculty of veterinary, Tabriz University, Tabriz, Iran \\ 3 Department of clinical pathology, Faculty of veterinary, Tehran University, Tehran, Iran
}

ITX020409A02 • Received: 16 April 2009 • Revised:25 May 2009 • Accepted:01 June 2009

\begin{abstract}
There are no reports of toxicological studies of Pterocarya fraxinifolia. The leaves are used for fishing, which also an anesthetic agent. Currently, many drugs utilized in anesthesia practice are modified cholinergic transmission and acetylcholine esterase inhibitors; these are parts of anaesthetic pharmacy. Therefore, cholinergic assessment was surveyed in chicken embryo, which Pterocarya fraxinifolia extractes were injected in 0.1, 1 and $10 \mathrm{mg}$ concentration at day 4 of incubation. Serum and brain cholinesterase were analyzed on day 20 of incubation. The signs were not due to the changes of cholinesterase activity. In histopathology examination, massive necrosis was observed in the spinal cord. Other tissues such as heart, kidneys, skeletal bones and muscles, trachea and lungs, digestive system and endocrine glands were completely developed. This data suggests that the spinal cord is a target organ of the bioactive component of this plant.
\end{abstract}

KEY WORDS: Pterocarya fraxinifolia; toxicity tests; cholinergic assessment; chicken embryotoxicity

\section{Introduction}

Pterocarya fraxinifolia is a fast-growing tree species naturally distributed throughout Western Blank Sea Region of Turkey and is native to the Caucasus from northern Iran to the Ukraine. Its leaves have antibacterial activity against Bacillus subtilis, antifungal activity against Candida albicans and Cladosporium cucumericum, as well as larvicidal activity against Aedes aegypti, and antioxidant (Azadbakht et al., 2005). 5-hydroxy-1, 4-naphthoquinone components or juglone that showing antimicrobial activities were found and determined in the leaves of this tree species (Hadjmohammadi and Kamyar, 2006).

The leaves have been used by Caucasian fisherman for catching fish. At present time, native people use these leaves as an anesthetic agent for fishing and for dyeing. Clinical observations showed this compound is remarkably similar to anesthetic compounds.

Correspondence addres:

Dr. Parisa Sadighara

Veterinary Faculty,

Azadi Street, Tehran University, Tehran, Iran

E-MAlL: parisa.sadighara@gmail.com
Many drugs currently used in anesthesia practice modify cholinergic transmission. Acetylcholine esterase inhibitors are part of the anaesthetic pharmacy (Kleinschmidt et al., 2005). AChE is an enzyme involved in cholinergic and noncholinergic functions in both the central and peripheral nervous system (Inestrosa et al., 2005). Therefore, our major hypothesis in the pathogenesis of neurotoxicity of this plant was anticholinesterase activity.

The purpose of this study was to evaluate neurotoxicity potential of this plant based on cholinesterase activity and histopathology.

\section{Materials and methods}

\section{Plant material}

The plant was collected in North of Iran and identified by Dr.Gholamreza Amin. Voucher specimen of this plant was deposited in the central herbarium of medicinal plants, Tehran University of Medical Sceiences. Pterocarya fraxinifolia leaves were separated, air dried in the shade, powdered and extracted in a soxhlet apparatus with a mixture of methanol-acetone-water (1:1:2 v/v/v) for $24 \mathrm{~h}$. The polar and non-polar compounds will be extracted by combination of different of solvents. After that time, the solvents are removed on a rotary evaporator. 


\section{Toxicity tests}

Chicken embryotoxicity study

Protocol of Chicken embryotoxicity study has gained acceptance by several regulating agencies (Anonymous, 1996). Fertile leghorn eggs were obtained from a breeding farm (Iran farm) on the second day. The eggs were injected on the fourth day. Extracts of Pterocarya fraxinifolia was injected in $0.1,1$ and $10 \mathrm{mg}$ concentration into the egg yolk. The dead embryos were fixed in $10 \%$ neutral formalin for microscopic examination. The experiment was terminated on day 20 of incubation. Embryos were removed; decapitated, observed malformation and gross lesions. Blood and brain of living embryos were collected for biochemical analysis.

\section{Cholinergic stress}

\section{Serum and brain cholinesterase assay}

The measurement of cholinesterase is well established. Potassium-phosphate buffer and DTNB was added to samples. Acetylthiocholine iodide was then added and the absorbance at $412 \mathrm{~nm}$ was read by spectrophotometer (Ellman et al., 1961).

\section{Microscopic lesion}

The tissue samples of dead embryos were fixed in $10 \%$ neutral formalin, embedded in paraffin, sectioned at 6 microns and stained with H\&E for histopathology.

\section{Results}

Results of Cholinergic Stress are presented in Table 1. Administration of the highest dose of the extraction resulted in $100 \%$ mortality of the embryos. In the treatment groups with concentrations of $0.1 \mathrm{mg}$ and $1 \mathrm{mg}$, rate of mortality was $50 \%$. However, high mortality will be observed if embryos are exposed to high concentration of a xenobiotic.

There was no significant difference $(p<0.05)$ in serum and brain cholinesterase activity. Brain cholinesterase activity was also not in a dose-response depended fashion between groups.

The microscopic section is showed in Figure 1. Primary malacia areas in the spinal cord as several ragged cavities scattered through various white columns especially in the dorsal funiculli of cervical region but were not symmetrical. In these foci of malacia, the large, irregular, empty

\begin{tabular}{|c|c|c|c|c|}
\hline & Control & $\begin{array}{c}0.1 \mathrm{mg} / \\
\mathrm{egg}\end{array}$ & $\begin{array}{l}1 \mathrm{mg} / \\
\mathrm{egg}\end{array}$ & $\begin{array}{c}10 \mathrm{mg} / \\
\mathrm{egg}\end{array}$ \\
\hline $\mathrm{N}$ & 10 & 10 & 10 & 10 \\
\hline Survival (\%) & $90 \%$ & $50 \%$ & $50 \%$ & 0 \\
\hline $\begin{array}{l}\text { Serum cholinesterase } \\
\text { assay (IU) }\end{array}$ & $0.34 \pm 0.08$ & $0.41 \pm 0.17$ & $0.42 \pm .012$ & 0 \\
\hline $\begin{array}{l}\text { Brain cholinesterase } \\
\text { assay (IU) }\end{array}$ & $0.68 \pm 0.07$ & $0.57 \pm 0.1$ & $0.71 \pm 0.09$ & 0 \\
\hline
\end{tabular}

cavities were presumably the result of pooling of myelin and liquefaction necrosis. The necrosis in spinal cord was considerable. Swollen axons were detected in cross section. These affected axons and were appeared as spherical, darkly stained structures or were absent. In sections cut of parallel to the length of the tract, axons were distorted, thickened in some segments and were fragmented at other points along the course and this tissue was vacuolated, spongy appearance, in contrast, normal white column in which myelin sheaths were uniform in diameter.

There was no decrease in hematopoiesis (granulopoiesis and erythropoiesis) in the bone marrow and extramedullary hematopoiesis centers within other tissues. Other tissues such as, heart, kidneys, skeletal bones and muscles, trachea and lungs, digestive system and endocrine glands were completely developed.

\section{Discussion}

In this study, for the first time, we carried out toxicology study of Pterocarya fraxinifolia with regard to cholinesterase activity and histopathology. It was supposed that this plant might inactivate cholinesterases. The hypothesis that this plant might inactivate cholinesterase was supported by studies that cholinesterases are measured as clinical parameter in neurotoxicity of anesthesia drugs. The studies had shown that barbiturate inhibits the specific activity of acetyl cholinesterase. Erythrocyte cholinesterase (E-ChE) activity was markedly reduced (20-40\%) after anaesthesia with $\mathrm{CO}_{2}$ (Deckardt et al., 2007). Some central depressants (e.g. chlorpromazine) reduced the appearance of acetylcholinesterase in the cerebrospinal fluid (Vogt et al., 1984). Nevertheless, in present study, we illustrated that the changes of acetylcholine esterase activity were not significant.

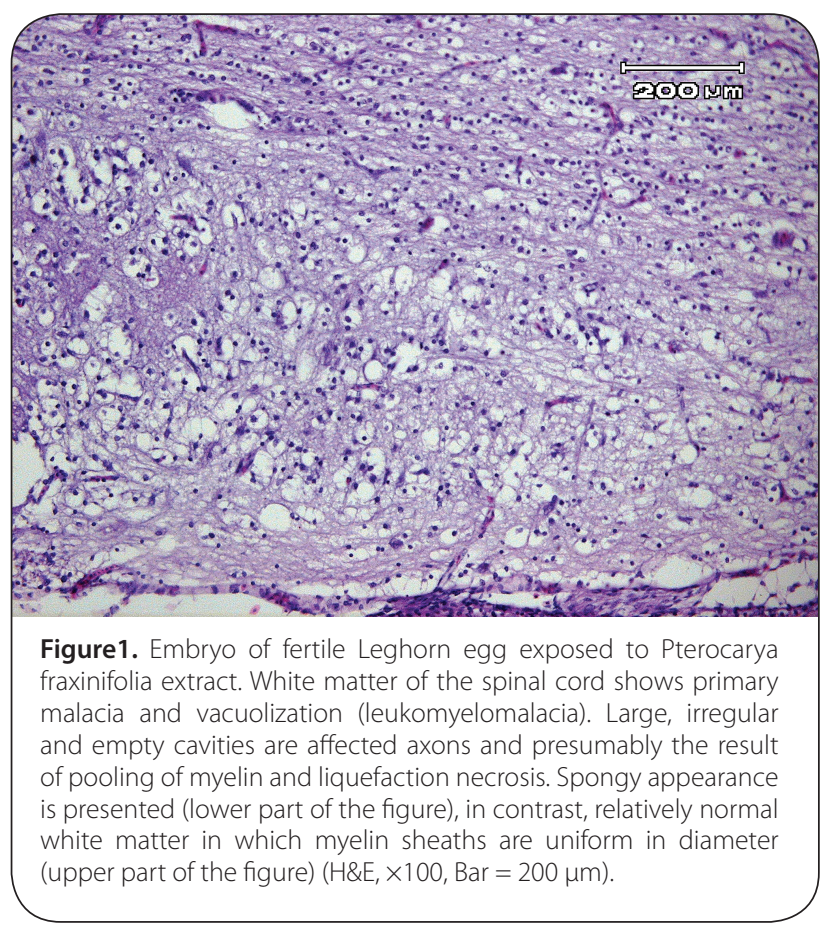


Morphological examinations are important in establishing the precise site of toxic lesions (Lu, 1996). Histopathology helps in identifying target organs of toxicity and mechanism of action (Wester et al., 2002). In histopathology examinations considerable liquefaction necrosis of the spinal cord and myelinated degeneration area were observed. There were no special histopatological changes in other organs.

Up to date, no toxicity tests have been performed on Pterocarya fraxinifolia. The results obtained in this study did not confirm neurotoxicity on chick embryo via cholinesterase activity and the observed signs were not due to the changes of cholinesterase activity. But, the spinal cord was microscopically identified as target organ.

Certainly, other in vitro and in vivo toxicological studies of Pterocarya fraxinifolia are needed. These assessments will provide the pharmacological safety dose, toxicity dose, and efficacy data from this plant. In the last decades, plant research has revealed several chemical compounds with important pharmacological activities. Some have been incorporated into drugs (Varanda et al., 2006). Therefore, it is possible that potential components with pharmacological effects could be isolated from Pterocarya fraxinifolia.

\section{REFERENCE}

Anonymous. (1996). Methode officielle d'evaluation du potential irritant par application sur la membrane chorio-allantoi-dienne de l'œuf de poule. Journal official de la republique francaise 19: 137-19138.

Azadbakht M, Marston A, Hostettmann K and Sadat Ebrahimi SE. (2005). Isolation of two naphthalene derivatives from Pterocarya Fraxinifolica leaf and evaluation of their biological activities. Chemistry: An Indian Journal 1: 780 783.

Deckardt K, Weber I, Kaspers U, Hellwig J, Tennekes H and van Ravenzwaay B. (2007). The effects of inhalation anaesthetics on common clinical pathology parameters in laboratory rats. Food Chem Toxicol 5: 1709-18.

Ellman G, Counrtney K, Andres VJR and Featherstone R. (1961). A new and rapid colorimetric determination of acetylcholinesterase activity: Biochemical pharmacology 7: 88-95.

Hadjmohammadi MR and Kamyar K. (2006). Determination of juglone(5-hydroxy 1, 4-naphthoquinone) in Pterocarya Fraxinifolia by RP-HPLC. Iran J Chem Chem Eng 25: 73-76.

Inestrosa NC, Sagal JP, Colombres M. (2005). Acetylcholinesterase interaction with Alzheimer amyloid beta. In Alzheimer's Disease: Cellular and Molecular Aspects of Amyloid $\beta$. (Harris JR and Fahrenholz F eds) pp. 299-317, Subcellular Biochemistry Vol. 38, Springer Science, New York.

Kleinschmidt S, Ziegeler S and Bauer C. (2005). Cholinesterase inhibitors. Importance in anaesthesia, intensive care medicine, emergency medicine and pain therapy. Anaesthesist 54: 791-9.

Lu FC. (1996). Basic Toxicology: Fundamentals, Target Organs, and Risk Assessment. Taylor \& Francis, Washington, D.C.

Varanda EA, Varella SD, Rampazo RA, Kitagawa RR, Goncalves Raddi MS, Vilegas W and Santos LC. (2006). Mutagenic and cytotoxic effect of planifolin: A naphthopyranone dimmer isolated from Paepalanthus Planifolius. Toxicology in vitro 20: 664-668.

Vogt M, Smith AD and Fuenmayor LD. (1984). Factors influencing the cholinesterases of cerebrospinal fluid in the anaesthetized cat. Neuroscience 12: 979 95.

Wester PW, Van LTM, Vethaak AD, Grinwis GCM and Vos JG. (2002). Aquatic toxicology opportunities for enhancement through histopathology. Environmental toxicology and pharmacology 11: 289-295. 